\title{
THE INFLUENCE OF THE TEACHING STRATEGY IN VOCATIONAL COLLEGE TO THE STUDENTS' JOB COMPETENCE
}

\author{
Chang, Tzu-Wai \\ Taipei College of Maritime Technology/ Chung Yuan Christian University \\ Taipei/ Chung Li, Taiwan \\ E-mail: donna.zhang@msa.hinet.net \\ Wang, Jen-Hung* \\ Chung Yuan Christian University \\ Chung Li, Taiwan \\ E-mail: doraemonponpon@ hotmail.com \\ Chang, Chia-Ying \\ Taipei College of Maritime Technology/ Chung Yuan Christian University \\ Taipei/ Chung Li, Taiwan \\ E-mail: f0993@mail.tcmt.edu.tw
}

\begin{abstract}
As the competition among job market, recruiting students among vocational colleges in Taiwan has become furious, so the teaching strategies need to match with the job competence for the competitiveness of students and of schools. The main purpose of our study is to examine the gap between business vocational education and employers' expectations. Therefore, we applied Delphi Technique to construct the final framework and Analytic Network Process (ANP) to evaluate the teaching priorities of teachers in vocational business education. Finally, we will advance our suggestions for the business vocational colleges as their reference.
\end{abstract}

Keywords: teaching priority, teaching strategy, job competence, Delphi technique, analytic network process (ANP)

\section{Introduction}

After the world financial crisis in 2007, job opportunities have become less, and job description in each job has increased in Taiwan. People perform more tasks in their job and work in long hours. Continue education in college and university has difficulty to recruit students. Moreover, due to the

\footnotetext{
* Corresponding author
} 
decreasing of birth rate, the higher education also has its problem to keep school operation. In the blue print of four years planning, the Taiwan Ministry of Education has announced that the future combination of universities and closing down among higher education is foreseeable (TTME, 2009). Therefore, strategies for recruiting enough students and sustaining funds for school operation are significances for school. The student enrollment standard is lowered, and the teachers also reduces students' burden in classes according to school policy. As the results, companies compliant about the difficulty of finding proper employees. This vicious cycle is running in current job market and education system in Taiwan. Thus, this study aims to examine the teaching priority of vocational business teachers because vocational business school graduates are normally skillful workers with low starting salary in Taiwanese job market.

We acquired our aspects and criteria from government conducted surveys and national surveys of several career focused magazines. The aspects and criteria are finalized by thoroughly discussion of five experts. Those experts are either job competence researchers or senior teachers in vocational colleges. Our study considers that between/ among aspects or criteria exist dependence more or less, so we take ANP (Analytic Network Process) as our major analytic tool to discuss and analyze the key aspects and the key criteria.

Our goal in this paper is to examine the linkage between job market and vocational college education by understanding the teaching priority of the teachers. The results will provide more insights and possible solutions to restructure the vocational education system in Taiwan.

\section{Literature Review}

\subsection{Vocational Education}

In the ancient time, the mentors/ teachers and families were two major streams to pass on their professional skills to the ir younger generations. This circumstance had been forced to change due to more comprehensive and complicated professional skills appeared after the Industrial Revolution. It also made our soc iety to pay more attention to the conception of vocational education. Furthermore, this vocational education system has been developed more completed and systematic until the early twenty century. As stated, the vocational education is aimed to enhance students' professional skills in order to develop more talented and successful people who can possess good professional ethics, great communication skill, independent thinking ability and problem solving capability (TTME, 2009).

Katz's definition of the management capabilities contains professional skill capability, communication capabilities and conception capability. Each different capability is closely related to the different professional ranking in a corporation or an organization. The lower-rank management is more 
significant on the professional skills and communication skill; the middle-rank management is more valued on all the professional skills, communication capability and conception capability; the high-rank management is more considered on the conception capability. However we shall acknowledge that companies pay more attention to the low-rank managements in training and cultivation.

\subsection{The Definitions and Origin of the Vocational Education Theory}

In the middle of 1960, the American government found out using the traditional way of "science and intelligent test" to interview and select the Foreign Service Information Officers (FSIO) that would be very difficult to predict which individual would have good performance on their profession in the future. Therefore, the American government requested McClelland and McBen Management Consultant Company to research an effective way to interview and to se lect a real talented individual. From the research, they approved that those who were in the good performance group would have better capability than those who were in the ordinary performance group, and that difference was caused by the competence conception (McClelland \& Dailey, 1972). Based on the research, in 1973, McClelland \& Dailey officially doubted the effectiveness of the traditional interview method in recruit people, and suggested the adaptation of the individual's competence because competence could avoid the prejudice of a person's intelligence, language ability and racial problem. For example, if you intent to know a person's driving skill, the best way is a driving test instead of a test in writing. Therefore, educators shall emphasize on competence of students in high education. Overall, competency ensures an individual to successfully conduct his/ her profession and fulfill his/ her task excellently (Klemp, 1980; Boyatzis, 1982; Ulrich, Brockbank, \& Yeung, 1989; Burgoyen, 1993; Mirabile, 1997). Generally, competency contains knowledge (Byham \& Moyer, 1996; Mirabile, 1997; Parry, 1998; Bonder, 2003), professional skills (Peak, 1980; Mirabile, 1997; Bonder, 2003), attitude (Peak, 1980; Parry, 1998) and motivation (Boyatzis, 1982; Byham \& Moyer, 1996) to conduct jobs and to achieve distinctive performances.

\subsection{The Dimension and Rule for Professional Competency of Vocational Management}

All organizations intend to recruit a right person for the right position in their businesses. However, different positions are required different competencies. Several scholars gave the insights of competency from their researches. Tsai et al. (2005), based on monitor industry, had established three dimensions of competency: attitude, communication, professional knowledge and skill. Researcher constructed nine common competencies which are positive, anti-pressure ability, creativity, communication skill, team-work, customer oriented, problem solving ability, learning ability and achievement oriented for the college students in places (Cheng et al., 2009). In a 2010 survey about fresher, it points out that when industries recruit their new starters, they weight their learning 
willingness and flexibility in a great value. Then, they gradually consider stability and anti-pressure ability, professional knowledge and skill, team cooperation, problem solving ability, international concept and foreign language, and creativity and comprehensive ability (Wu, 2010). Lio et al. (2006) did a similar survey of the essential competency for newly graduates. It not only listed out above-mentioned abilities but also added more factors like: understand and obey the professional ethic, career planning ability, knowledge of the industrial environment and development, job application and self marketing ability, and the ability of applying learned theory to works.

To sum up, traditionally, we think that the professional and general knowledge is the key for one to complete his/ her outstanding performance. As researchers concluded, the communication and expression ability, learning ability, problem solving ability, positive personality, anti-pressure ability, creativity, customer service tendency and team cooperation are also important parts of a person's competency.

\section{Establish the framework}

\subsection{Scope and Object}

Our scope is the business vocational colleges in Taiwan, and the objects are the teachers who teach in these schools.

\subsection{The Steps of Establishing Framework}

Step 1: Establish the embryonic framework by literature review.

Step 2: Interview five professional scholars to know the ir opinions for our embryonic framework, and revise it by their suggestions. The results are: Aspect A, Train the students'working attitude of employment and the ability of cooperation, has six criteria. Aspect B, Train the students, management of career planning and the ability of positive learning, has six criteria. Aspect $C$, Train the students for having the professional knowledge and skills, has nine criteria. AspectD, School Strategy, has five criteria. Aspect E, Government Strategy, has five criteria.

Step 3: Interview the same expert group, and let them fill in the score about the dependence between criteria. The score range is from 0 (no dependence) to 100 (full dependence). We take 60, 70, and 80 as our threshold limit value, and make three frameworks. Then, we consult our expert group that which framework is much fitter the practical environment. Finally, they decide to take 80 as the final threshold limit value. Moreover, the decision not only enhances the participants' willingness to answer but also increases the rate of accuracy. 


\section{Methodology}

Saaty advanced ANP (Analytic Network Process) in 1996 that is a multi-criteria method. AHP (Analytic Hierarchy Process) is a one-way hierarchical relational structure, but ANP allows more complex relationships between the decision levels and attributes. ANP takes network to replace hierarchical feedback, and the decision analysis is used in the high and low hierarchy or the directional relationship which is not obvious (Meade \& Sarkis, 1999). In ANP, when nodes correspond to levels or components, it means that there exists the network feedback in a system (Saaty, 1980). The elements in the nodes may influence some or all elements in other nodes. In the network, all the nodes can be source nodes, intermediate nodes or sink nodes. The dependence relationship in network is represented by the arc and the direction of arrow (Saaty, 1996). When the two nodes have the external dependence, it will be represented by the two-way arrow; when the nodes in the elements have the internal dependence, it will be represented by the circle arc (Sarkis, 2003).

\section{REFERENCES}

Bonder, A. (2003). A blueprint for the future: Competency-based management in HRDC. Unpublished presentation, HRDC Canada.

Boyatzis, R.E. (1982). The competent manager: A model for effective performance. NY: John Wiley \& Sons.

Burgoyne, J.G (1993). The competence movement: Issues, stakeholders and prospects. Personnel Review, 22(6), 6-13.

Byham, W.C., \& Moyer, R.P. (1996). Using competencies to build a successful organization. Pittsburgh, PA: Development Dimensions International Inc.

Cheng, N.S., Lin, P.C., \& Cheng, Y.C. (2009). Developing the competence inventory for college students. Psychological Testing, 56(3), 397-430.

Klemp, GO. Jr. (1980). The assessment of occupational competence. Washington, D.C.: National Institute of Education.

Lio, M.C., Chiou. J.R., \& Hu, J.L. (2006). Enhance job competency in education system: College graduates survey, The National Youth Commission.

McClellan, D.C., \& Dailey, C. (1972). Improving officer selection for the foreign service. American Psychologist.

McClellan, D.C., \& Dailey, C. (1973). Testing for competence rather than for intelligence. American Psychologist.

Meade, L.M., \& Sarkis, J. (1999). Analyzing organizational project alternatives for agile manufacturing processes: An analytical network approach. International Journal of Production Research, 37(2), 241-261. 
Mirabile, R.J. (1997). Everything you wanted to know about competency modeling. Training and Development, 73-77.

Parry, S.B. (1998). Just what is a Competency? And why should you care?. Training, 35(6), 58-64.

Peak, L. (1980). A conceptual framework and process: For identifying the in service needs of vocational educators serving special needs populations, Dept. of Vocational and Technical Education, University of Minnesota, MN.

Saaty, T.L. (1980). The analytic hierarchy process. New York, NY: McGraw-Hill.

Saaty, T.L. (1996). Decision making with dependence and feedback: The analytic network process. Pittsburgh, PA: RWS Publications.

Sarkis, J. (2003). Quantitative models for performance measurement systems - alternate considerations. International Journal of Production Economics, 86(1), 81-90.

The Taiwan Ministry of Education (TTME) (2009). http://www.edu.tw/content.aspx?site_content_sn=541 (accessed on 29, January, 2011).

The Taiwan Ministry of Education (TTME) (2009). http://www.edu.tw/files/site_content/EDU01/980703\%b1\%d0\%a8\%7c\%b3\%a1\%acI\%acF\% c2\%c5\%b9\%cf\%c5\%e9\%a8t\%aa\%ed.pdf (accessed on 29, January, 2011).

The Taiwan Ministry of Education (TTME) (2009). http://www.edu.tw/files/site_content/EDU01/.pdf (accessed on 29, January, 2011).

The Taiwan Ministry of Education (TTME) (2009). http://history.moe.gov.tw/important_list.asp (accessed on 29, January, 2011).

Tsai, M.C., Chang, C.C., \& Lee, J.H. (2005). A study on the competence and job performance of the mainland China direct employees - in case of Taiwanese enterprises of component parts of monitors, Business Review, 10(1), 53-74.

Ulrich, D., Brockbank, W., \& Yeung, A. (1989). HR competencies in the 1990s: An empirical assessment of what the future holds. Personnel Administration, 34, 91-93.

Wu, Y.C. (2010). 2010 Taiwan 1000 enterprises survey. Working for Happy Future, 35, 164-172. 